\title{
Neonatal screening for congenital adrenal hyperplasia
}

\author{
E CACCIARI, A BALSAMO, A CASSIO, S PIAZZI, F BERNARDI, S SALARDI, \\ A CICOGNANI, P PIRAZZOLI, F ZAPPULLA, M CAPELLI, AND M PAOLINI \\ 2nd Pediatric Clinic, University of Bologna, and Central Laboratory, \\ $S$ Orsola Hospital of Bologna, Italy
}

SUMNARY Capillary blood samples from 42930 infants born in the Italian region of EmiliaRomagna were collected for 17-hydroxyprogesterone radioimmunoassays on days 2, 3, 4, 5, 6, and 7, or between days 7 and 15 of life. A microfilter paper method modified from that of Pang et al. ${ }^{1}$ was used for this assay. Pathologic values of 17-hydroxyprogesterone were found in 5 infants giving an incidence in this homogeneous Caucasian population of $1: 8586$. We also investigated 17-hydroxyprogesterone values in relation to the day of sampling and the possible correlation between 17-hydroxyprogesterone values and birthweight and gestational age. We concluded that neonatal screening for congenital adrenal hyperplasia caused by 21 -hydroxylase deficiency was possible by this method and that the infants' maturity and the particular day of collection of the samples affect the values but not the validity of the screening.

The considerable variation in the reported incidence of congenital adrenal hyperplasia $(\mathrm{CAH})^{2-8}$ may be explained partially by the lack of a valid screening method. We have reported on $\mathrm{CAH}$ screening in 22233 neonates $^{9}$ in the region of Emilia-Romagna in Italy (a ho nogeneous Caucasian population) and in this study we enlarge on and update that information. We screened 42930 infants for CAH caused by 21 -hydroxylase deficiency by assaying 17-hydroxyprogesterone (17-OHP) values. In addition we investigated 17-OHP values in relation to the sampling day and a possible correlation between 17-OHP values and gestational age and birthweight.

\section{Materials and methods}

Capillary blood samples taken from $\mathbf{4 2} 930$ neonates and collected on filter paper (Sleicher and Schuell) were used to determine 17-OHP concentrations. A microfilter paper (1/8 inch diameter paper disc) method modified from that of Pang et al. ${ }^{1}$ that has been reported previously ${ }^{10}$ was used. Blood samples were taken on day 2 of life from 134 infants $(0.2 \%)$, on day 3 from $801(2.1 \%)$, on day 4 from 6945 $(15.3 \%)$, on day 5 from $19271(46 \%)$, on day 6 from $9063(2 \cdot 8 \%)$, and on day 7 from $1660(3.4 \%)$. The remaining 5056 samples $(12 \cdot 2 \%)$ were collected between days 7 and 15 of life.

For the first 1634 infants screened a 17-OHP concentration as high as $9 \mathrm{pg} /$ disc was regarded as a threshold value calling for a repeat test. We found that infants with 17-OHP concentrations up to 20 $\mathrm{pg} /$ disc had no clinical or biochemical evidence of $\mathrm{CAH}$, however, and a new threshold was set at $\mathbf{2 0}$ $\mathrm{pg} / \mathrm{disc}$ for the remaining infants. Where values were higher than this they were confirmed by a second assay and the serum 17-OHP concentration was determined.

Day of sampling, gestational age, and birthweight were all considered in the analysis of the results. With regard to gestational age, infants were divided into 2 groups; either 'term'-those delivered between 37 weeks and 42 weeks of gestation, or 'preterm'delivered before 37 weeks' gestation. The data reported here include only those infants who were screened using a threshold value of $20 \mathrm{pg} /$ disc.

Statistical analysis was performed using Student's $t$ test and $\chi^{2}$ test and the correlation coefficient ' $r$ ' was calculated. The 95 th percentile confidence limits of estimated incidence rate were calculated according to the confidence limits for the expectation of the Poisson variable. ${ }^{11}$ The gene frequency and the carrier frequency were calculated according to the Hardy-Weinberg law ${ }^{12}$ which states that:

Gene frequency = square root of the incidence of the homozygous state.

Heterozygote frequency $=2 \mathrm{pq}$; where $\mathrm{p}=$ frequency of normal gene and $q=$ frequency of CAH gene. 
Table 1 Clinical and hormonal features of the 5 infants with congenital adrenal hyperplasia

\begin{tabular}{|c|c|c|c|c|c|c|}
\hline \multirow[t]{2}{*}{ Case No } & \multirow[t]{2}{*}{ Age (Days) } & \multirow[t]{2}{*}{ Gestation } & \multirow[t]{2}{*}{ Birthweight $(g) \quad 3$} & \multicolumn{2}{|c|}{ 17-OHP value } & \multirow[t]{2}{*}{ External genitalia } \\
\hline & & & & $\begin{array}{l}\text { 1st spot } \\
\text { (pg/disc) }\end{array}$ & $\begin{array}{l}\text { Serum } \\
(\text { (ng/dl) }\end{array}$ & \\
\hline $1(\mathrm{M})$ & $\begin{array}{r}4 \\
24\end{array}$ & Term & 4000 & $>250$ & $>5000$ & Mild macrogenitosomia \\
\hline $2(F)$ & $\begin{array}{r}5 \\
150\end{array}$ & Term & 3300 & $28^{*}$ & 5000 & Ambiguous \\
\hline $3(F)$ & $\begin{array}{r}5 \\
30\end{array}$ & Term & 3870 & 47 & 1400 & Normal \\
\hline $4(F)$ & $\begin{array}{r}4 \\
14\end{array}$ & Term & 3000 & $>250$ & $>5000$ & Ambiguous \\
\hline $5(F)$ & $\begin{array}{l}3 \\
7\end{array}$ & Term & 3200 & $>250$ & $>5000$ & Ambiguous \\
\hline
\end{tabular}

*This patient's blood, collected on filter paper, was stored in unfit conditions, which may explain her relatively low 17-OHP value.

\section{Results}

Eighty eight $(0 \cdot 2 \%)$ of the 42930 infants tested showed a 17-OHP value beyond the threshold of $20 \mathrm{pg} / \mathrm{disc}$ and were retested (Table 2). Retest blood samples were taken from 2 of the children $(0.25 \%)$ initially tested on day 3 of life, from $2(0.03 \%)$ initially tested on day 4 , from $25(0.13 \%)$ on day 5 , from $20(0.22 \%)$ on day 6 , from $10(0.6 \%)$ on day 7 , and from $29(0.57 \%)$ after day 7 . In 5 of the infants who were retested $(5.7 \%)$ the pathologic values were confirmed giving an incidence of 1:8586 neonates. These infants had a 17-OHP value $>20 \mathrm{pg} /$ disc and were born at term; their clinical and hormonal details are summarised in Table 1.

Table 2 shows the concentrations of 17-OHP in relation to the day of sampling. No statistically significant differences were found between the various days. The number and percentage of second tests according to gestational age (term and preterm) are set out in Table 3 . The percentage was slightly higher for preterm infants. Retest percentages and 17-OHP values according to gestational age and birthweight are shown in Figs. 1 and 2.

Table 2 Relation between 17-hydroxyprogesterone values and day of sampling

\begin{tabular}{crlll}
\hline Day & Cases & $\begin{array}{l}\text { Value pg/disc } \\
(\text { mean }(S D))\end{array}$ & $\begin{array}{l}\text { Retest } \\
\text { cases }\end{array}$ & $\begin{array}{l}\text { Retest } \\
(\%)\end{array}$ \\
\hline 2 & 134 & $5 \cdot 73(1 \cdot 03)$ & & $0 \cdot 00$ \\
3 & 801 & $6 \cdot 18(2 \cdot 19)$ & 2 & $0 \cdot 25$ \\
4 & 6,945 & $6 \cdot 82(2 \cdot 83)$ & 2 & $0 \cdot 03$ \\
5 & 19,271 & $6 \cdot 73(2 \cdot 99)$ & 25 & $0 \cdot 13$ \\
6 & 9,063 & $7 \cdot 74(3 \cdot 25)$ & 20 & $0 \cdot 22$ \\
7 & 1,660 & $9 \cdot 15(9 \cdot 55)$ & 10 & $0 \cdot 60$ \\
$>7$ & 5,056 & $8 \cdot 96(8 \cdot 93)$ & 29 & 0.57 \\
\hline Total & 42930 & & 88 & 0.2 \\
\hline
\end{tabular}

Table 3 Number and percentage of retests according to gestational age (term and preterm)

\begin{tabular}{lcl}
\hline & Patients tested $(\%)$ & Retested $(\%)$ \\
\cline { 2 - 3 } Term infants & $37,364(90.47)$ & $27(0.07)^{*}$ \\
Preterm infants & $3,935(9.53)$ & $61(1.55)^{*}$ \\
\hline
\end{tabular}

${ }^{*} \chi^{2}=298(\mathrm{P}<0.000001)$.

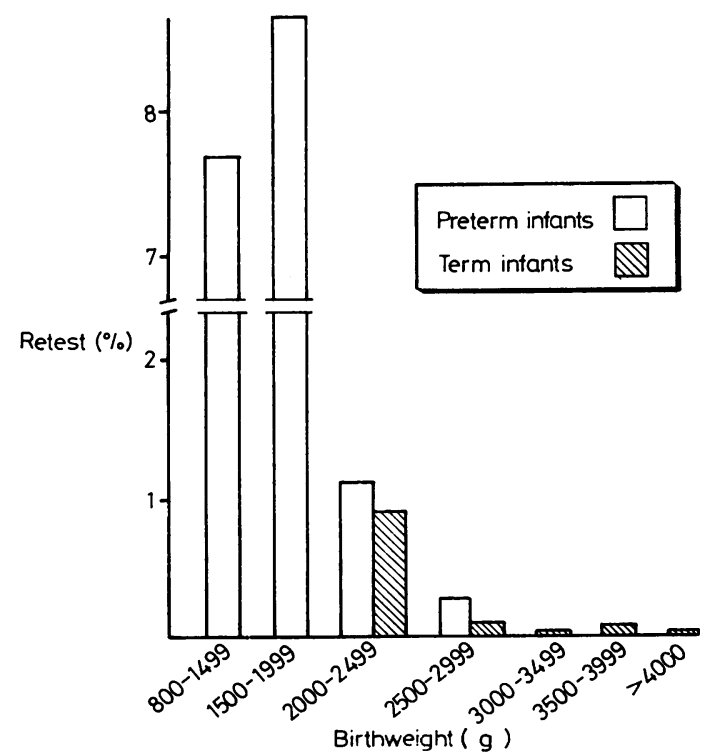

Fig. 1 Retest percentage according to gestational age (term and preterm) and birthweight.

$\mathbf{P}<0.001$ between group with birthweight $<2500 \mathrm{~g}$ and all other groups (as regards the children born at term);

$\mathbf{P}<0.001$ between groups with birthweight $800-2000 \mathrm{~g}$ and the groups with birthweight $>2000 \mathrm{~g}$ (as regards the preterm children);

$\mathbf{P}<0.05$ between term and preterm children in the group with birthweight 2500-3000 g. 


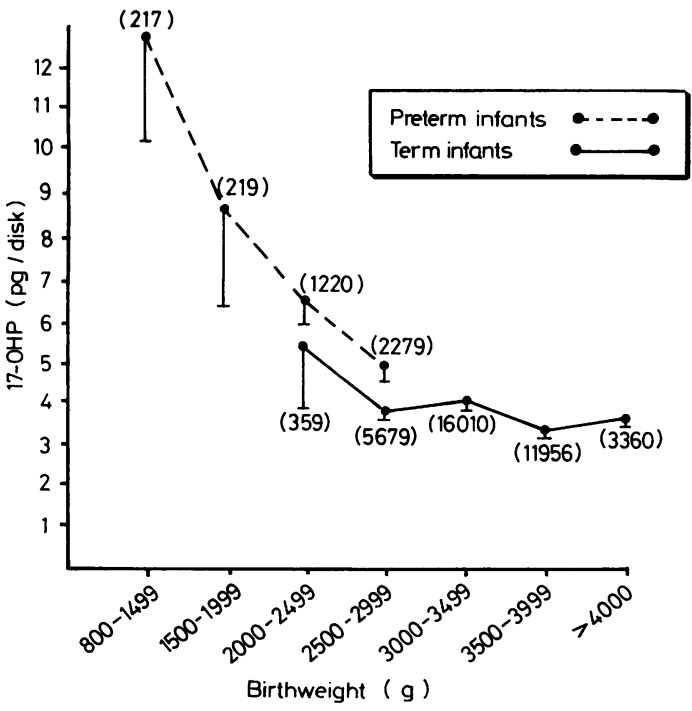

Fig. 2 17-hydroxyprogesterone values (pg/disc) SD according to gestational age (term and preterm) and birthweight. (In brackets number of cases.)

$\mathrm{P}<0.05$ between group with birthweight $<2500 \mathrm{~g}$ and the groups with birthweight $>3500 \mathrm{~g}$ (as regards the children born at term); $\mathrm{P}<0.001$ between group with birthweight $800-1500 \mathrm{~g}$ and the group with birthweight $>2000 \mathrm{~g}$ (as regards the preterm children);

$\mathrm{P}<0.05$ between term and preterm children in the group with birthweight $2500-3000 \mathrm{~g}$.

Among term infants, the group with birthweight $<2500 \mathrm{~g}$ had a higher retest percentage than all other groups $(P<0.001)$, and the 17-OHP concentrations were higher than those of infants with birthweight $3500 \mathrm{~g}(\mathrm{P}<0.05)$. Among preterm infants the retest percentage in the groups of infants with birthweight between 800 and $2000 \mathrm{~g}$ was similar, and was higher $(P<0.001)$ than for those groups with a birthweight $>2000 \mathrm{~g}$. The 17-OHP value was greater $(\mathrm{P}<0.001)$ in infants weighing $800-1500 \mathrm{~g}$ than in those $>2000 \mathrm{~g}$. In infants of $1500-2000 \mathrm{~g}$ the 17-OHP concentration was greater than in infants weighing $>2500 \mathrm{~g}$.

The difference in retest percentages was significant $(\mathrm{P}<0.05)$ between term and preterm infants in the group with birthweight 2500-3000 g. The 17-OHP value was greater in preterm than in term infants $(P<0.05)$. A negative correlation existed $(P<0.05)$ between birthweight and 17-OHP values in retested infants.

The direct cost for each screening test was US $\$ 1.63(£ 1.05)$ and this included wages for laboratory staff and all expenses for reagents and supplies.

\section{Discussion}

This is the first study to evaluate the true prevalence of $\mathrm{CAH}$ in a homogeneous Caucasian population using a reliable method. The reported incidence of CAH varies internationally from 1:490 among Alaskan Eskimos to $1: 67000$ in the United States. ${ }^{2-8}$ In these reports the lack of accurate screening procedures may have made it difficult to assess the incidence. Some infants may have eluded detection because of neonatal death and some boys with delayed virilisation may have been diagnosed as cases of precocious puberty.

Our investigation shows that the incidence of CAH with or without salt loss in the Emilia-Romagna region is $1: 8586$ live births. This corresponds with a heterozygote incidence of $1: 47$ for CAH is transmitted as an autosomal recessive trait. The gene frequency is 0.011 . The lower and upper 95th percentile confidence limits of these estimated incidence rates indicate that the incidence of $\mathrm{CAH}$ may be as high as 1:3678 live births and as low as 1:26 500 live births for homozygous affected cases and as high as $1: 30.8$ and as low as $1: 81.8$ for heterozygous cases. The 95 th percentile confidence limits of the gene frequency are 0.016-0.006.

The 5 infants with raised 17-OHP concentrations (4 girls and 1 boy) included 3 with salt loss (Table 1, cases 1, 4, and 5), 1 infant had a classic case of CAH without salt loss (Table 1, case 2), and in 1 patient (Table 1, case 3) a diagnosis of late onset ${ }^{13-15}$ or cryptic form ${ }^{16}$ of CAH, based on a high 17-OHP value with no clinical signs, was made. The patients in cases $1,2,3$, and 4 have been described. ${ }^{9}$ Screening made it possible to establish a precise and timely diagnosis and to decide on treatment in the patients in cases 1 and 4.

With a 17-OHP threshold value of $20 \mathrm{pg} /$ disc the number of repeat tests was not appreciably affected by the day on which the samples had been collected. Children examined on day 2 of life showed lower mean values of 17-OHP than those examined later, but this was not statistically significant. This finding may be ascribed to the fact that sampling was usually done before leaving the obstetric ward and it is possible that the infants examined and considered fit to be moved on days 2 and 3 of life were the most mature and therefore showed lower 17-OHP values. In any case, it is evident that by day 2 of life the 17-OHP values were no longer affected by placental production. Those neonates examined from day 7 onward were mostly recovering from premature birth or low birthweight for dates. The stage of adrenal maturity of these infants varied considerably and this may explain the range of values and the higher retest percentage (Tables 2 and 3).

Our study showed that although the number of 
repeat tests in preterm infants was high, the 17-OHP value quickly became normal when prematurity was not complicated by other factors. This is confirmed by the first follow up, usually made within the third week of life.

The analysis of retest percentages and 17-OHP values in relation to birthweight and gestational age (Figs. 1 and 2) indicated that the latter had greater influence on adrenal enzymatic maturity in infants of birthweight $>2500 \mathrm{~g}$, whereas birthweight seemed to be more important in infants $<2500 \mathrm{~g}$. In terms of both retest percentages and 17-OHP values an appreciable difference existed between term and preterm infants weighing $2500-3000 \mathrm{~g}$ but this difference was not found in the group of infants with birthweight 2000-2500 g.

The number of false positives $(0 \cdot 2 \%)$ was acceptable, but we believe that this could be reduced further. Preterm infants and those of birthweight $<2500 \mathrm{~g}$ were recalled most frequently and in future we would increase the threshold value to $30 \mathrm{pg} / \mathrm{disc}$ for these infants. We were not aware of any false negative values.

We conclude that: (1) neonatal screening for CAH is possible using micropaper discs impregnated with capillary blood and that it is convenient to carry it out in the same laboratory that screens for phenylketonuria and hypothyroidism; (2) immaturity of the neonates and the particular day of sampling affect the value of 17-OHP but not the validity of the screening; (3) although these data alone do not justify wide scale or even national screening for $\mathrm{CAH}$, greater experience is needed before a definite conclusion may be drawn.

We thank Doctor M I New for her comments and advice during the preparation of this paper.

\section{References}

1 Pang S, Hotchkiss J, Drash AL, Levine LS, New MI. Microfilter paper method for 17- $\alpha$-hydroxyprogesterone radioimmunoassay: its application for rapid screening for congenital adrenal hyperplasia. $J$ Clin Endocrinol Metab $1977 ; 45: 1003-8$.
2 Hirschfield AJ, Fleshman JK. An unusually high incidence of salt-losing congenital adrenal hyperplasia in the Alaskan Eskimo. J Pediatr 1969;75:492-4.

${ }^{3}$ Qazi QH, Thompson WM. Incidence of salt losing form of congenital virilizing congenital hyperplasia. Arch Dis Child 1972;47:302-7.

4 Hubble D. Congenital adrenal hyperplasia. In: Holts KS, Raine DN, eds. Basic concepts of inborn errors and defects of steroid biosintesis. Proc. 3rd Symp Society for the study of inborn errors of metabolism. Edinburgh: Livingstone, 1966:68-75.

5 Rosenbloom AL, Smith DW. Congenital adrenal hyperplasia (letter). Lancet 1966 ;i:660.

6 Prader A. Die häufigkeit des kongenitalen adrenogenitalen Syndroms. Helv Paediatr Acta 1958;13:426-31.

7 Childs B, Grumbach MM, Van Wyk JJ. Virilizing adrenal hyperplasia. A genetic and hormonal study. $J$ Clin Invest 1956;35:213-21.

8 Pang S, Murphy W, Levine LS, et al. A pilot newborn screening for congenital adrenal hyperplasia $(C A H)$ due to 21-hydroxylase deficiency at New York Hospital and Alaska. 1st Joint Meeting LWPES-ESPE Geneva, 1981.

9 Cacciari E, Balsamo A, Cassio A, et al. Neonatal screening for congenital adrenal hyperplasia using a microfilter paper method for 17- $\alpha$-hydroxyprogesterone radioimmunoassay. Experience gained from the study of 22,233 cases. Horm Res 1982;16:4-9.

10 Piazzi S, Capelli M, Paolini M, et al. Neonatal screening for 21-hydroxylase deficiency: a microfilter paper method for 17- $\alpha$-hydroxyprogesterone assay. $J$ Endocrinol Invest $1982 ; 5: 87-90$.

11 Diem K, Lentner C. Scientific Tables. 7th edition. Switzerland: Ciba Geigy Limited, 1972:188.

12 Fristrom JW, Spieth PT. Principles of genetics. New York: Chiron Press, 1980:533.

13 Zachmann M, Prader A. Unusual heterozygotes of congenital adrenal hyperplasia due to 21-hydroxylase deficiency. Acta Endocrinol (Copenh) 1978;87:557-65.

14 Blankstein J, Faiman C, Reyes FI, Shroeder M,L Winter JSD. Adult-onset familial adrenal 21-hydroxylase deficiency. Am J Med 1980;68:441-8.

15 New MI, Lorenzen F, Pang S, Gunczler P, Dupont B, Levine LS. 'Acquired' adrenal hyperplasia with 21hydroxylase deficiency is not the same genetic disorder as congenital adrenal hyperplasia. J Clin Endocrinol Metab $1979 ; 48: 356-9$.

16 Levine LS, Zachmann M, New MI, et al. Genetic mapping of the 21-hydroxylase-deficiency gene within the HLA linkage group. $N$ Engl J Med 1978;299:911-15.

Correspondence to Professor E Cacciari, Clinica Pediatrica II, Università di Bologna, Via Massarenti II, 40138 Bologna, Italy.

Received 10 May 1983 